\title{
Insulin adjustment by a diabetes nurse educator improved glucose control in patients with poorly controlled, "insulin requiring" diabetes
}

Thompson DM, Kozak SE, Sheps S. Insulin adjustment by a diabetes nurse educator improves glucose control in insulin-requiring diabetic patients: a randomized trial. CMAJ 1999 Oct 19;161:959-62.

QUESTION: Does regular telephone advice by a diabetes nurse educator for insulin adjustment improve glucose control in patients with poorly controlled, "insulin requiring" diabetes?

\section{Design}

Randomised (allocation concealed), blinded (outcome assessor), controlled trial with 6 months of follow up.

\section{Setting}

Hospital diabetes clinic in Vancouver, British Columbia, Canada.

\section{Patients}

46 patients with diabetes (mean age 49 y, $52 \%$ women) who had a glycated haemoglobin $\left(\mathrm{HbA}_{1 c}\right)$ levels $\geqslant 8.5 \%$, were on insulin therapy, had received standard diabetes education, were able to monitor blood glucose levels at home, and were receiving care by an endocrinologist. Exclusion criteria were inability to have regular telephone communication, contraindication to tight glucose control, other serious illness, or use of an insulin pump. Follow up was $100 \%$.

\section{Intervention}

Patients were allocated to receive regular telephone contact with a diabetes nurse educator for advice about adjustment of insulin therapy (nurse telephone intervention, $\mathrm{n}=23$ ) or to continue regular clinic visits and usual contact with the endocrinologist for insulin adjustment (standard care, $\mathrm{n}=23$ ). Patients in the nurse telephone intervention group received about 3 telephone calls per week, each of about 15 minutes duration.

\section{Main outcome measures}

Mean $\mathrm{HbA}_{1 \mathrm{c}}$ level and proportion of patients in each group who achieved a reduction in $\mathrm{HbA}_{1 \mathrm{c}}$ level of $\geqslant 10 \%$.

\section{Main results}

At 6 months, compared with patients who received standard care, those who received the nurse telephone intervention had a lower mean $\mathrm{HbA}_{1 c}$ level $(8.9 \%$ v 7.8\%, $\mathrm{p}<0.01$ ). A higher proportion of patients in the nurse telephone intervention group had a reduction in $\mathrm{HbA}_{1 \mathrm{c}}$ of $\geqslant 10 \%(\mathrm{p}<0.001)$ (table).

\section{Conclusion}

Regular telephone advice on insulin adjustment by a diabetes nurse educator improved glucose control in patients with poorly controlled, "insulin requiring" diabetes.

Nurse telephone intervention v standard care for patients with poorly controlled, "insulin requiring" diabetes*

\begin{tabular}{|c|c|c|c|c|}
\hline $\begin{array}{l}\text { Outcome at } \\
6 \mathrm{mo}\end{array}$ & Intervention & $\begin{array}{l}\text { Standard } \\
\text { care }\end{array}$ & $\begin{array}{l}\text { RBI } \\
(95 \% \mathrm{Cl})\end{array}$ & $\begin{array}{l}\text { NNT } \\
\text { (CI) }\end{array}$ \\
\hline $\begin{array}{l}\text { Reduction in } \\
\mathrm{HbA}_{1 \mathrm{c}} \text { level } \\
\text { of } \geqslant 10 \%\end{array}$ & $87 \%$ & $35 \%$ & $\begin{array}{l}150 \% \\
\text { (50 to } 369)\end{array}$ & $\begin{array}{l}2 \\
\text { (1 to } 4)\end{array}$ \\
\hline
\end{tabular}

*Abbreviations defined in glossary; $\mathrm{RBI}, \mathrm{NNT}$, and $\mathrm{Cl}$ calculated from data in article.

\section{COMMENTARY}

There is a need to expand the evidence base that examines the role of diabetes nurse educators. Although insulin adjustment by telephone advice is an integral part of the diabetes nurse educator's role, evaluation of this intervention is lacking.

This study by Thompson et al is well designed. It is a randomised controlled trial, includes 6 months of follow up data on all patients who began the study, and avoids bias by ensuring that the laboratory technicians determining the $\mathrm{HbA}_{1 \mathrm{c}}$ levels were blinded to the patients' group assignment. Although we are given some information about the patients in the study, we do not know their ethnic background and socioeconomic status, which may influence the generalisability of the study findings. With respect to generalisability, it is also important to note that the telephone counselling was done by only 1 experienced nurse who was responsible for a small number of patients. The authors acknowledge that it is possible that the nurse was uniquely qualified and that the same results may not be achieved with larger numbers of patients or with nurses with different training, experience, or characteristics. However, the study findings are consistent with other studies evaluating regular telephone contact with nurses. ${ }^{1}$

The study findings have huge resource implications for diabetes nursing (the telephone advice for the 23 patients in the intervention group took approximately $17 \mathrm{~h} / \mathrm{wk}$ of nursing time). However, both the Diabetes Control and Complications Trial ${ }^{3}$ and the United Kingdom Prospective Diabetes Study $y^{4}$ showed that good glycaemic control is associated with a decreased risk of long term macrovascular and microvascular diabetes complications, and that even lowering the $\mathrm{HbA}_{1 c}$ level by $1 \%$ makes a difference. Given the potential for long term cost saving effects of this expensive intervention, a proper cost effectiveness analysis is warranted.

Eileen Turner, RN, RNT, MSc Lecturer/Practitioner, Diabetes Care King's College Hospital Denmark Hill, London, UK

1 Thompson DM, Dansereau J, Creed M et al. Tight glucose control results in normal perinatal outcome in 150 patients with gestational diabetes. Obstet Gynecol 1994;83:362-6.

2 Von Korff M, Gruman J, Schaefer J et al. Collaborative management of chronic illness. Ann Intern Med 1997;127:1097 102.

3 The Diabetes Control and Complications Trial Research Group. The effect of intensive treatment of diabetes on the development and progression of long-term complications in insulin-dependent diabetes mellitus. $N$ Engl $J$ Med 1993;329:977-86.

4 UK Prospective Diabetes Study (UKPDS) Group. Intensive blood-glucose control with sulphonylureas or insulin compared with conventional treatment and risk of complications in patients with type 2 diabetes (UKPDS 33). Lancet 1998;352:837-53. 